International Journal of Current Advanced Research

ISSN: O: 2319-6475, ISSN: P: 2319 - 6505, Impact Factor: SJIF: 5.995

Available Online at www.journalijcar.org

Volume 6; Issue 4; April 2017; Page No. 3104-3106

DOI: http://dx.doi.org/10.24327/ijcar.2017.3106.0194

\title{
QUASI $\hat{\hat{g}}$-OPEN AND QUASI $\hat{\hat{g}}$-CLOSED FUNCTIONS \\ Manoj Garg
}

Department and Research Centre of Mathematics, Nehru Degree College, Chhibramau, Kannauj, U.P., India

A R T I C L E I I N F O

Article History:

Received $17^{\text {th }}$ January, 2017

Received in revised form $8^{\text {th }}$ February, 2017

Accepted $22^{\text {nd }}$ March, 2017

Published online $28^{\text {th }}$ April, 2017

Key words:

$\hat{\hat{g}}$-open set, $\hat{\hat{g}}$-closed set, $\hat{\hat{g}}$-interior, $\hat{\hat{g}}$ -

closure, quasi $\hat{\hat{g}}$-open function.
A B S T R A C T

The purpose of this paper is to give a new type of open function called quasi $\hat{\hat{g}}$-open function. Further, we obtain its characterizations and its basic properties. 2000 Mathematics Subject Classification: 54c10, 54c08, 54c05.

Copyright $₫ 2017$ Manoj Garg. This is an open access article distributed under the Creative Commons Attribution License, which permits unrestricted use, distribution, and reproduction in any medium, provided the original work is properly cited.

\section{INTRODUCTION}

\section{Preliminaries}

Functions in particular open functions play an important role in mathematical science. Many different forms of open functions have been introduced over the years. Its importance is significant in various areas of mathematics and related sciences.

Recently, as a generalization of closed sets, the notion of $\hat{\hat{g}}$ closed sets were introduced and studied by Manoj et al [3]. Manoj et al [4] further introduced the concept of $\hat{\hat{g}}$-open functions. In the present paper, we will continue the study of related functions by involving $\hat{\hat{g}}$-open sets and $\hat{\hat{g}}$-open functions. Further, we introduce and characterize the concept of quasi $\hat{\hat{g}}$-open functions.

Throughout this paper, spaces mean topological spaces on which no separation axioms are assumed unless otherwise mentioned and $\mathrm{f}:(\mathrm{X}, \tau) \rightarrow(\mathrm{Y}, \sigma)$ (or simply $\mathrm{f}: \mathrm{X} \rightarrow \mathrm{Y}$ ) denotes a function $\mathrm{f}$ of a space $(\mathrm{X}, \tau)$ into a space $(\mathrm{Y}, \sigma)$. Let $A$ be a subset $A$ of space $X$. The closure and the interior of $A$ are denoted by $\operatorname{cl}(\mathrm{A})$ and $\operatorname{int}(\mathrm{A})$, respectively.

*Corresponding author: Manoj Garg

Department and Research Centre of Mathematics, Nehru

Degree College, Chhibramau, Kannauj, U.P., India
Definition 1.1: A subset A of a topological space $(X, \tau)$ is called semi-open [2] (resp. semiclosed) if $\mathrm{A} \subseteq \operatorname{cl}(\operatorname{int}(\mathrm{A})$ ) $($ resp. $\operatorname{int}(\mathrm{cl}(\mathrm{A})) \subseteq \mathrm{A})$.

The semi-closure [1] of A subset of $X$, denoted by $\operatorname{scl}(\mathrm{A})$, is defined to be the intersection of all semi-closed sets containing $\mathrm{A}$ in $\mathrm{X}$.

Definition 1.2: A subset A of a topological space $(X, \tau)$ is called

1. Semi generalized-closed (briefly sg-closed) [2] if $\operatorname{scl}(\mathrm{A}) \subseteq \mathrm{U}$ whenever $\mathrm{A} \subseteq \mathrm{U}$ and $\mathrm{U}$ is semi-open in $\mathrm{X}$. The complement of sg-closed set is called sgopen. set.

2. (ii) $\hat{\hat{g}}$-closed [3] if $\operatorname{cl}(\mathrm{A}) \subseteq \mathrm{U}$ whenever $\mathrm{A} \subseteq \mathrm{U}$ and $\mathrm{U}$ is sg-open in $\mathrm{X}$. The complement of $\hat{\hat{g}}$-closed set is called $\hat{\hat{g}}$-open set.

The union (resp. intersection) of all $\hat{\hat{g}}$-open (resp. $\hat{\hat{g}}$-closed) sets, each contained in (resp. containing) a set $\mathrm{A}$ in space $\mathrm{X}$ is called the $\hat{\hat{g}}$-interior (resp. $\hat{\hat{g}}$-closure) of A and is denoted by $\hat{\hat{g}}-\operatorname{Int}(\mathrm{A})(\operatorname{resp} . \hat{\hat{g}}-\mathrm{cl}(\mathrm{A}))[4]$.

Definition 1.3: A function $\mathrm{f}:(\mathrm{X}, \tau) \rightarrow(\mathrm{Y}, \square)$ is called 
1. $\hat{\hat{g}}$-irresolute [3] (resp $\hat{\hat{g}}$-continuous [3]) if the inverse image of every $\hat{\hat{g}}$-closed set (resp. $\sigma$-closed set) in $\mathrm{Y}$ is $\hat{\hat{g}}$-closed in $\mathrm{X}$.

2. $\hat{\hat{g}}$-open [4] (resp. $\hat{\hat{g}}$-closed [4]) if $\mathrm{f}(\mathrm{V})$ is $\hat{\hat{g}}$-open (resp. $\hat{g}$-closed) in Y for every open (resp. closed) subset of $X$

3. $\hat{\hat{g}} *$-closed [4] if the image of every $\hat{\hat{g}}$-closed subset of $\mathrm{X}$ is $\hat{\hat{g}}$-closed in $\mathrm{Y}$.

Definition 1.4: Let $\mathrm{x}$ be a point of $(\mathrm{X}, \tau)$ and $\mathrm{N}$ be a subset of $\mathrm{X}$. Then $\mathrm{N}$ is called a $\hat{\hat{g}}$-neighbourhood (briefly $\hat{\hat{g}}$-nbd) [4] of $\mathrm{x}$ if there exists a $\hat{\hat{g}}$-open set $\mathrm{G}$ such that $\mathrm{x} \in \mathrm{G}$ and $\mathrm{G} \subset$ N.

\section{Quasi $\hat{\hat{\mathbf{g}}}$-open Functions}

In this section we introduce the following definitions.

Definition 2.1: A function $\mathrm{f}:(\mathrm{X}, \tau) \rightarrow(\mathrm{Y}, \sigma)$ is said to be quasi $\hat{\hat{g}}$-open if the image of every $\hat{\hat{g}}$-open set in $\mathrm{X}$ is open in $\mathrm{Y}$.

Clearly the concepts of quasi $\hat{\hat{g}}$-openness and $\hat{\hat{g}}$-continuity coincide if the function $\mathrm{f}$ is bijective.

Theorem 2.1: A function $\mathrm{f}: \mathrm{X} \rightarrow \mathrm{Y}$ is quasi $\hat{\hat{g}}$-open iff for every subset $A$ of $X, f(\hat{\hat{g}}-\operatorname{Int}(\mathrm{A})) \subseteq \operatorname{Int}(\mathrm{f}(\mathrm{A}))$.

Proof: Let $\mathrm{f}$ be a quasi $\hat{\hat{g}}$-open function. Since $\operatorname{Int}(\mathrm{A})) \subseteq \mathrm{A}$ and $\hat{\hat{g}}$-Int $(\mathrm{A})$ is a $\hat{\hat{g}}$-open set so $\mathrm{f}(\hat{\hat{g}}-\operatorname{Int}(\mathrm{A})) \subseteq(\mathrm{f}(\mathrm{A}))$. As $\mathrm{f}($ $\hat{\hat{g}}-\operatorname{Int}(\mathrm{A}))$ is open, $\mathrm{f}(\hat{\hat{g}}-\operatorname{Int}(\mathrm{A})) \subseteq \operatorname{Int}(\mathrm{f}(\mathrm{A}))$.

Conversely, let A be $\hat{\hat{g}}$-open set in $\mathrm{X}$ such that $\mathrm{f}(\hat{\hat{g}}-\operatorname{Int}(\mathrm{A}))$ $\subseteq \operatorname{Int}(\mathrm{f}(\mathrm{A}))$. Then $\mathrm{f}(\mathrm{A})=\mathrm{f}(\hat{\hat{g}}-\operatorname{Int}(\mathrm{A})) \subseteq \operatorname{Int}(\mathrm{f}(\mathrm{A}))$. But $\operatorname{Int}(\mathrm{f}(\mathrm{A})) \subseteq \mathrm{f}(\mathrm{A})$ so $\mathrm{f}(\mathrm{A})=\operatorname{Int}(\mathrm{f}(\mathrm{A}))$ and hence $\mathrm{f}$ is quasi $\hat{\hat{g}}$ open.

Lemma 2.1: If a function $\mathrm{f}: \mathrm{X} \rightarrow \mathrm{Y}$ is quasi $\hat{\hat{g}}$-open, then $\hat{\hat{g}}$ $-\operatorname{Int}\left(\mathrm{f}^{-1}(\mathrm{~A})\right) \subseteq \mathrm{f}^{-1}(\operatorname{Int}(\mathrm{A}))$ for every subset $\mathrm{A}$ of $\mathrm{Y}$.

Proof : Let U be any arbitrary subset of Y. Then $\hat{\hat{g}}-\operatorname{Int}(\mathrm{f}$ $\left.{ }^{1}(\mathrm{~A})\right)$ is a $\hat{\hat{g}}$-open set in $\mathrm{X}$ and $\mathrm{f}$ is quasi $\hat{\hat{g}}$-open then $\mathrm{f}(\hat{\hat{g}}$ $\left.\operatorname{Int}\left(\mathrm{f}^{-1}(\mathrm{~A})\right)\right) \subseteq \operatorname{Int}\left(\mathrm{f}\left(\mathrm{f}^{-1}(\mathrm{~A})\right) \subseteq \operatorname{Int}(\mathrm{U})\right.$. Thus, $\hat{\hat{g}}-\operatorname{Int}\left(\mathrm{f}^{-1}(\mathrm{~A})\right) \subseteq$ $\mathrm{f}^{-1}(\operatorname{Int}(\mathrm{A}))$.

Theorem 2.2: For a function $\mathrm{f}: \mathrm{X} \rightarrow \mathrm{Y}$, the following are equivalent

1. f is quasi $\hat{\hat{g}}$-open;

2. For each subset $A$ of $X, f(\hat{\hat{g}}-\operatorname{Int}(\mathrm{A})) \subseteq \operatorname{Int}(\mathrm{f}(\mathrm{A}))$;
3. For each $\mathrm{x} \in \mathrm{X}$ and each $\hat{\hat{g}}$-nbd $\mathrm{A}$ of $\mathrm{x}$ in $\mathrm{X}$, there exists a neighborhood $\mathrm{B}$ of $\mathrm{f}(\mathrm{x})$ in $\mathrm{Y}$ such that $\mathrm{B} \subseteq$ $\mathrm{f}(\mathrm{A})$.

Proof : (i) $\Rightarrow$ (ii) Follows from theorem (2.1).

(ii) $\Rightarrow$ (iii) Let $\mathrm{x} \in \mathrm{X}$ and $\mathrm{A}$ be an arbitrary $\hat{\hat{g}}$-nbd of $\mathrm{X}$ in $\mathrm{X}$. Then there exists a $\hat{\hat{g}}$-open set $\mathrm{B}$ in $\mathrm{X}$ such that $\mathrm{x} \in \mathrm{B} \subseteq \mathrm{A}$. Then by (ii), $\mathrm{f}(\mathrm{B})=\mathrm{f}(\hat{\hat{g}}-\operatorname{Int}(\mathrm{B}))$ $\subseteq \operatorname{Int}(\mathrm{f}(\mathrm{B}))$ and hence $\mathrm{f}(\mathrm{B})=\operatorname{Int}(\mathrm{f}(\mathrm{B})$. Thus $\mathrm{f}(\mathrm{B})$ is open in $Y$ such that $\mathrm{f}(\mathrm{x}) \in \mathrm{f}(\mathrm{B}) \subseteq \mathrm{f}(\mathrm{A})$.

(iii) $\Rightarrow$ (i) Let $\mathrm{A}$ be an arbitrary $\hat{\hat{g}}$-open set in $\mathrm{X}$. Then for each $y \in f(A)$, by (iii) there exists a nbd. $B_{y}$ of $y$ in $Y$ such that $B_{y} \subseteq f(A)$. Since $B_{y}$ is a nbd. of $y$ so there exists an open set $\mathrm{C}_{\mathrm{y}}$ in $\mathrm{Y}$ such that $\mathrm{y} \in \mathrm{C}_{\mathrm{y}} \subseteq$ $B_{y}$. Thus $\mathrm{f}(\mathrm{A})=\cup\left\{\mathrm{C}_{\mathrm{y}}: \mathrm{y} \in \mathrm{f}(\mathrm{A})\right.$ which is an open set in $\mathrm{Y}$. Thus $\mathrm{f}$ is quasi $\hat{\hat{g}}$-open function.

Theorem 2.3 : A function $\mathrm{f}: \mathrm{X} \rightarrow \mathrm{Y}$ is quasi $\hat{\hat{g}}$-open iff for any subset $\mathrm{A}$ of $\mathrm{Y}$ and for any $\hat{\hat{g}}$-closed set $\mathrm{F}$ of $\mathrm{X}$ containing $\mathrm{f}^{-1}(\mathrm{~A})$ there exists a closed set $\mathrm{C}$ of $\mathrm{Y}$ containing $\mathrm{A}$ such that $\mathrm{f}^{-1}(\mathrm{C}) \subseteq \mathrm{F}$.

Proof: Suppose that $\mathrm{f}$ is quasi $\hat{\hat{g}}$-open function. Let $\mathrm{A} \subseteq \mathrm{Y}$ and $\mathrm{F}$ be a $\hat{\hat{g}}$-closed set of $\mathrm{X}$ containing $\mathrm{f}^{-1}(\mathrm{~A})$. Put $\mathrm{C}=\mathrm{Y}-$ $\mathrm{f}(\mathrm{X}-\mathrm{F})$. It is clear that $\mathrm{f}^{-1}(\mathrm{~A}) \subseteq \mathrm{F}$ implies $\mathrm{A} \subseteq \mathrm{C}$. Since $\mathrm{f}$ is quasi $\hat{\hat{g}}$-open, we obtained $\mathrm{C}$ as a closed set of $\mathrm{Y}$. Also $\mathrm{f}^{-1}(\mathrm{C})$ $\subseteq \mathrm{F}$.

Conversely, let $\mathrm{U}$ be $\hat{\hat{g}}$-open set in $\mathrm{X}$. Put $\mathrm{A}=\mathrm{Y} \backslash \mathrm{f}(\mathrm{U})$ then $\mathrm{X} \backslash \mathrm{U}$ is a $\hat{\hat{g}}$-closed set in $\mathrm{X}$ containing $\mathrm{f}^{-1}(\mathrm{~A})$. By hypothesis, there exists a closed set $F$ of $Y$ such that $A \subseteq F$ and $\mathrm{f}^{1}(\mathrm{~F}) \subseteq$ $\mathrm{X} \backslash \mathrm{U}$. Hence $\mathrm{f}(\mathrm{U}) \subseteq \mathrm{Y} \backslash \mathrm{A}$. Again $\mathrm{A} \subseteq \mathrm{F}, \mathrm{Y} \backslash \mathrm{F} \subseteq \mathrm{Y} \backslash \mathrm{A}=$ $\mathrm{f}(\mathrm{U})$. Thus $\mathrm{f}(\mathrm{U})=\mathrm{Y} \backslash \mathrm{F}$ which is open and hence $\mathrm{f}$ is a quasi $\hat{\hat{g}}$-open function.

Theorem 2.4: A function $\mathrm{f}: \mathrm{X} \rightarrow \mathrm{Y}$ is quasi $\hat{\hat{g}}$-open iff $\mathrm{f}$ ${ }^{1}(\mathrm{cl}(\mathrm{A})) \subseteq \hat{\hat{g}}-\operatorname{cl}\left(\mathrm{f}^{-1}(\mathrm{~A})\right)$ for every subset $\mathrm{A}$ of $\mathrm{Y}$.

Proof: Follows from theorem (2.3).

Lemma 2.2: Let $\mathrm{f}: \mathrm{X} \rightarrow \mathrm{Y}$ and $\mathrm{g}: \mathrm{Y} \rightarrow \mathrm{Z}$ be two functions and gof $: X \rightarrow Z$ is quasi $\hat{\hat{g}}$-open. If $\mathrm{g}$ is continuous injective, then $\mathrm{f}$ is quasi $\hat{\hat{g}}$-open.

Proof: Let A be a $\hat{\hat{g}}$-open set in X. Then $(\mathrm{gof})(\mathrm{A})$ is open in $\mathrm{Z}$, since gof is quasi $\hat{\hat{g}}$-open. Again $\mathrm{g}$ is an injective continuous function, $f(A)=g^{-1}(\operatorname{gof}(A))$ is open in $Y$. Thus $f$ is quasi $\hat{\hat{g}}$-open.

Quasi $\hat{\mathbf{g}}$ - closed Functions 
In this section we introduce the following definitions.

Definition 3.1: A function $\mathrm{f}:(\mathrm{X}, \tau) \rightarrow(\mathrm{Y}, \sigma)$ is called quasi $\hat{\hat{g}}$-closed if the image of each $\hat{\hat{g}}$-closed set in $\mathrm{X}$ is closed in Y.

Clearly every quasi $\hat{\hat{g}}$-closed function is closed and $\hat{\hat{g}}$ closed.

Remark 3.1: Every $\hat{\hat{g}}$-closed (resp. closed) function need not be quasi $\hat{\hat{g}}$-closed as shown by the following example.

Example 3.1: Let $\mathrm{X}=\mathrm{Y}=\{\mathrm{a}, \mathrm{b}, \mathrm{c}\}, \tau=\{\phi,\{\mathrm{a}, \mathrm{b}\}, \mathrm{X}\}$ and $\sigma=\{\phi,\{a\},\{a, b\}, Y\}$. Define $f:(X, \tau) \rightarrow(Y, \sigma)$ by identity mapping then $\mathrm{f}$ is $\hat{\hat{g}}$-closed and closed but not quasi $\hat{\hat{g}}$ closed.

Lemma 3.1: If a function $\mathrm{f}: \mathrm{X} \rightarrow \mathrm{Y}$ is quasi $\hat{\hat{g}}$-closed, then $\mathrm{f}$ ${ }^{1}(\operatorname{Int}(\mathrm{A})) \subseteq \hat{\hat{g}}-\operatorname{Int}\left(\mathrm{f}^{-1}(\mathrm{~A})\right)$ for every subset $\mathrm{A}$ of $\mathrm{Y}$.

Proof: Proof is similar to Lemma (2.1).

Theorem 3.1 : A function $\mathrm{f}=: \mathrm{X} \rightarrow \mathrm{Y}$ is quasi $\hat{\hat{g}}$-closed iff for any subset $A$ of $Y$ and for any $\hat{\hat{g}}$-open set $G$ of $X$ containing $\mathrm{f}^{-1}(\mathrm{~A})$, there exists an open set $\mathrm{H}$ of $\mathrm{Y}$ containing $\mathrm{A}$ such that $\mathrm{f}^{-1}(\mathrm{H}) \subseteq \mathrm{G}$.

Proof: Proof is similar to theorem (2.3).

Theorem 3.2: If $\mathrm{f}: \mathrm{X} \rightarrow \mathrm{Y}$ and $\mathrm{g}: \mathrm{Y} \rightarrow \mathrm{Z}$ are two quasi $\hat{\mathrm{g}}$ closed function, then their composition gof $: \mathrm{X} \rightarrow \mathrm{Z}$ is a quasi $\hat{\hat{g}}$-closed function.

Proof: Proof is definition based.

Theorem 3.3: Let $\mathrm{f}: \mathrm{X} \rightarrow \mathrm{Y}$ and $\mathrm{g}: \mathrm{Y} \rightarrow \mathrm{Z}$ be any two functions then

(i) If $\mathrm{f}$ is $\hat{\hat{g}}$-closed and g is quasi $\hat{\hat{g}}$-closed, then gof is closed.

(ii) If $\mathrm{f}$ is quasi $\hat{\hat{g}}$-closed and $\mathrm{g}$ is $\hat{\hat{g}}$-closed, then gof is $\hat{\hat{g}} *$-closed.

(iii) If $\mathrm{f}$ is $\hat{\hat{g}} *$-closed and $\mathrm{g}$ is quasi $\hat{\hat{g}}$-closed, then gof is quasi $\hat{\hat{g}}$-closed.

Proof: Proof is straight forward.

Theorem 3.4: Let $\mathrm{f}: \mathrm{X} \rightarrow \mathrm{Y}$ and $\mathrm{g}: \mathrm{Y} \rightarrow \mathrm{Z}$ be two functions such that their composition gof $: \mathrm{X} \rightarrow \mathrm{Z}$ is quasi $\hat{\hat{g}}$-closed

(i) If $\mathrm{f}$ is $\hat{\hat{g}}$-irresolute serjective, then $\mathrm{g}$ is closed.

(ii) If $\mathrm{g}$ is $\hat{\hat{g}}$-continuous injective, then $\mathrm{f}$ is $\hat{\hat{g}} *$ closed.

Proof: (i) Let F be an arbitrary closed set in Y. Since $f$ is $\hat{\hat{g}}$-irresolute, $\mathrm{f}^{-1}(\mathrm{~F})$ is $\hat{\hat{g}}$-closed in $\mathrm{X}$. Again since gof is quasi $\hat{g}$-closed and $\mathrm{f}$ is surjective, $\left(\operatorname{gof}\left(\mathrm{f}^{-1}(\mathrm{~F})\right)\right)=\mathrm{g}(\mathrm{F})$ is closed set in $\mathrm{Z}$. Thus $\mathrm{g}$ is closed function.

(i) Let $\mathrm{F}$ be any $\hat{\hat{g}}$-closed set in X. Since gof is quasi $\hat{\hat{g}}$-closed, (gof)(F) is closed in Z. Again g is $\hat{\hat{g}}$ continuous and injective function, $\mathrm{g}^{-1}(\operatorname{gof}(\mathrm{F}))=$ $\mathrm{f}(\mathrm{F})$ is $\hat{\hat{g}}$-closed in $\mathrm{Y}$. Thus $\mathrm{f}$ is $\hat{\hat{g}} *$-closed.

Theorem 3.5: Let $\mathrm{X}$ and $\mathrm{Y}$ be two topological spaces. Then the function $\mathrm{g}: \mathrm{X} \rightarrow \mathrm{Y}$ is a quasi $\hat{\hat{g}}$-closed if and only if $\mathrm{g}(\mathrm{X})$ is closed in $Y$ and $g(A) \backslash g(X \backslash A)$ is open in $g(X)$ whenever $A$ is $\hat{\hat{g}}$ open in $\mathrm{X}$.

Proof: Let $\mathrm{g}: \mathrm{X} \rightarrow \mathrm{Y}$ is a quasi $\hat{\hat{g}}$-closed function. Since $\mathrm{X}$ is $\hat{\hat{g}}$ closed, $\mathrm{g}(\mathrm{X})$ is closed in $\mathrm{Y}$ and $\mathrm{g}(\mathrm{A}) \backslash \mathrm{g}(\mathrm{X} \backslash \mathrm{A})=\mathrm{g}(\mathrm{A}) \cap \mathrm{g}(\mathrm{X}) \backslash$ $g(X \backslash A)$ is open in $g(X)$ when $A$ is $\hat{\hat{g}}$-open in $X$.

Conversely, let $g(X)$ is closed in $Y, g(A) \backslash g(X \backslash A)$ is open in $\mathrm{g}(\mathrm{X})$ when $\mathrm{A}$ is $\hat{\hat{g}}$-open in $\mathrm{X}$, and let $\mathrm{B}$ be closed in $\mathrm{X}$. Then $\mathrm{g}(\mathrm{B})$ $=g(X) \backslash(g(X \backslash B) \backslash g(B))$ is closed in $g(X)$ and hence, closed in $Y$.

Corollary 3.1: Let $\mathrm{X}$ and $\mathrm{Y}$ be two topological spaces. Then a surjection function $\mathrm{g}: \mathrm{X} \rightarrow \mathrm{Y}$ is quasi $\hat{\hat{g}}$-closed if and only if $\mathrm{g}(\mathrm{A})$ $\backslash \mathrm{g}(\mathrm{X} \backslash \mathrm{A})$ is open in $\mathrm{Y}$ whenever $\mathrm{V}$ is $\hat{\hat{g}}$-open in $\mathrm{X}$.

Corollary 3.2: Let $\mathrm{X}$ and $\mathrm{Y}$ be two topological spaces and let $\mathrm{g}$ : $\mathrm{X} \rightarrow \mathrm{Y}$ be $\hat{\hat{g}}$-continuous, quasi $\hat{\hat{g}}$-closed surjective function. Then the topology on $Y$ is $\{g(A) \backslash g(X \backslash A): A$ is $\hat{\hat{g}}$-open in $X\}$.

Proof: Let $\mathrm{B}$ be open in $\mathrm{Y}$. Then $\mathrm{g}^{-1}(\mathrm{~B})$ is $\hat{\hat{g}}$-open in $\mathrm{X}$ and $\mathrm{g}\left(\mathrm{g}^{-}\right.$ ${ }^{1}(B) \backslash g\left(X \backslash g^{-1}(B)\right)=B$. Hence all open sets in $Y$ are of the form $\mathrm{g}(\mathrm{A}) \backslash \mathrm{g}(\mathrm{X} \backslash \mathrm{A}), \mathrm{A}$ is $\hat{\hat{g}}$-open in $\mathrm{X}$. On the other hand, all sets of the form $g(A) \backslash g(X \backslash A), A$ is $\hat{\hat{g}}$-open in $X$, are open in $Y$ from corollary (3.1).

Definition 3.3 : A topological space $(\mathrm{X}, \tau)$ is said to be $\hat{\hat{g}}$-normal if for any pair of disjoint $\hat{\hat{g}}$-closed subsets $\mathrm{F}_{1}$ and $\mathrm{F}_{2}$ of $\mathrm{X}$, there exists disjoint open sets $\mathrm{U}$ and $\mathrm{V}$ such that $\mathrm{F}_{1} \subseteq \mathrm{U}$ and $\mathrm{F}_{2} \subseteq \mathrm{V}$.

Theorem 3.6: Let $\mathrm{X}$ and $\mathrm{Y}$ be topological spaces with $\mathrm{X}$ is $\hat{\hat{g}}$ normal. If $\mathrm{g}: \mathrm{X} \rightarrow \mathrm{Y}$ is a $\hat{\hat{g}}$-continuous, quasi $\hat{\hat{g}}$-closed, surjective function then $\mathrm{Y}$ is normal.

\section{References}

1. Crossley S.G. and Hildebrand S.K.: Semi closure, Texas j.Sci., 22 (1971), 99-112.

2. Levine N: Semi open sets and semi continuity in topological spaces, Amer. Math. Monthly, 70 (1963), 36-41.

3. Garg M., Agarwal S. and Goel C. K.: On $\hat{\hat{g}}$-closed sets in topological spaces, Acta. Cinecia Indica vol. XXXII M., 4 (2007) 1643-1652.

4. Garg M., Agarwal S. and Goel C. K.: On $\hat{\hat{g}}$-homeomorphisms in topological spaces, Ultra $\quad$ Sci.19(3)(2007), 697-706. 